\title{
Polysyndactyly and Marfan's syndrome
}

\author{
K. FRIED and G. MUNDEL \\ Departments of Genetics and Paediatrics, Asaf Harofe Government Hospital, Tel-Aviv University Medical School, \\ Zerifin, Israel
}

\begin{abstract}
Summary. An Egyptian Jewish family in which polysyndactyly is transmitted through four generations with 17 affected individuals is presented. The malformation is caused by an autosomal dominant gene with full penetrance and variable expressivity. In the newborn propositus the gene was fully expressed producing polysyndactyly of both hands and both feet. The mother had polysyndactyly of the feet but only syndactyly of the third and fourth fingers of the right hand and a post minimi on the left hand. In addition she had Marfan's syndrome due to a new mutation and transmitted Marfan's syndrome to one of her daughters who did not have polysyndactyly. Apparently the association of Marfan's syndrome with polysyndactyly has not been previously described.
\end{abstract}

Various forms of dominantly inherited polydactyly as well as syndactyly are known as separate conditions; these malformations are also part of well known syndromes. The literature was reviewed and families were reported by Thomsen (1927), McClintic (1935), Goodman (1965), and by Temtamy and McKusick (1969). In those families one gene caused both anomalies and the description of the anomalies is very similar to the malformations occurring in the family presented here.

\section{The Family}

The propositus (IV.16, Fig. 1) was born after a normal pregnancy. Polysyndactyly of both feet and hands was noticed immediately after birth. There was no other pathological finding and the infant was thriving. The malformations of the feet consisted of duplication of the first toe, partial syndactyly of the duplicated toes, and complete cutaneous syndactyly of the second and third toes with the adjacent duplicated toe. There was also partial cutaneous syndactyly between the third and fourth toes (Fig. 2). The malformations of the right hand were partial splitting of the distal part of the thumb, complete cutaneous syndactyly of the second, third, fourth, and fifth fingers with the distal part of the fingers more intimately connected, the long and narrow finger nails touching each other (the area of actual skin fusion was limited to a narrow strip along the lateral and volar part of the fingers), and a post minimi was attached to the fifth finger (Fig. 3). The abnormality of the left

Received 9 October 1973. hand was similar to that of the right except that the syndactyly between the fourth and fifth was only partial and consisted of only a skin web (Fig. 4).

The mother of the proposita (III.4, Fig. 1) was a Jewish immigrant from Egypt. She was 27 years old at the birth of propositus. She had several operations because of her polysyndactyly. Her feet (Fig. 5) show her toes after plastic operations for separation of the toes and removal of one of the duplicated big toes on the left foot. She had a small scar on the lateral aspect of her fifth finger on the left hand as a result of removal of a post minimi in infancy. There was only cutaneous syndactyly between the third and fourth fingers on the right hand which had been partially corrected by plastic surgery. Her fingers were long and slender (Fig. 6) and she had hyperextensibility of the joints. She was relatively tall (Fig. 7) compared to the height of her parents and sibs who were all of low stature. Her height was $173 \mathrm{~cm}$ and span $175 \mathrm{~cm}$. She had mild scoliosis and kyphosis. At the age of 16 she underwent an operation because of bilateral lens subluxation and the lenses were removed. She also had an umbilical hernia operated on at the age of 24. Her sclerae were bluish and her palate was narrow. Radiological examination revealed dilatation of the first part of the ascending aorta.

This woman had both polysyndactyly and Marfan's syndrome. Her father (II.3) was of low stature (164 $\mathrm{cm}$ ) and did not show any sign of Marfan's syndrome when last examined at the age of 59 . He had very wide thumbs with the nail split on the left thumb. The big toes of both feet were duplicated but completely fused so that they appeared like huge flattened first toes; he was 32 years old at the birth of III.4. The mother of III.4 

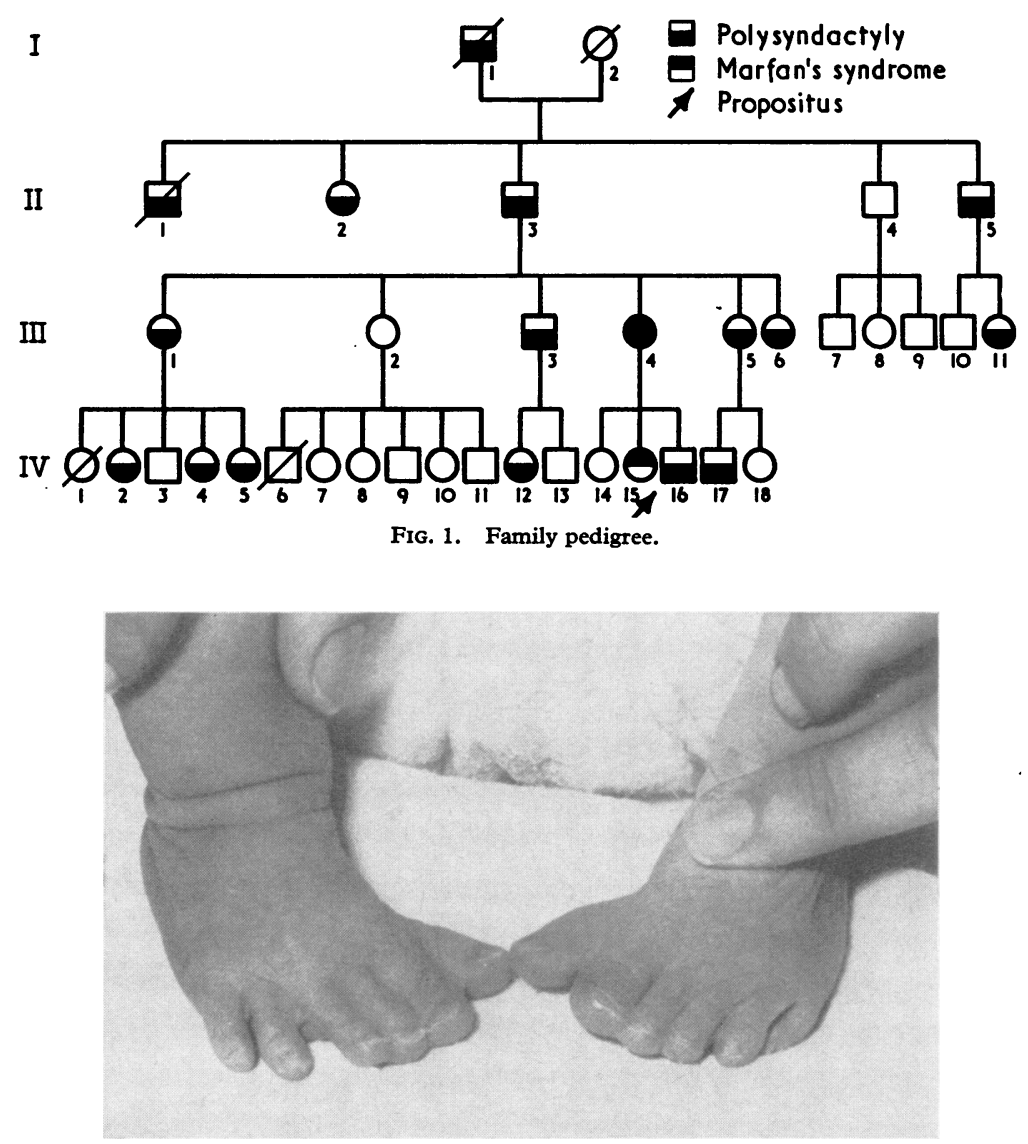

FIG. 2. Feet of the propositus (IV.16).

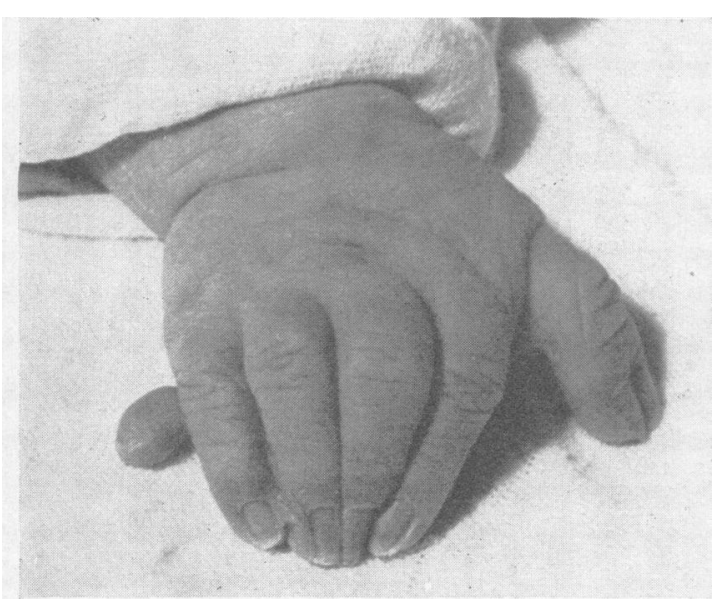

FIG. 3. Right hand of the propositus.

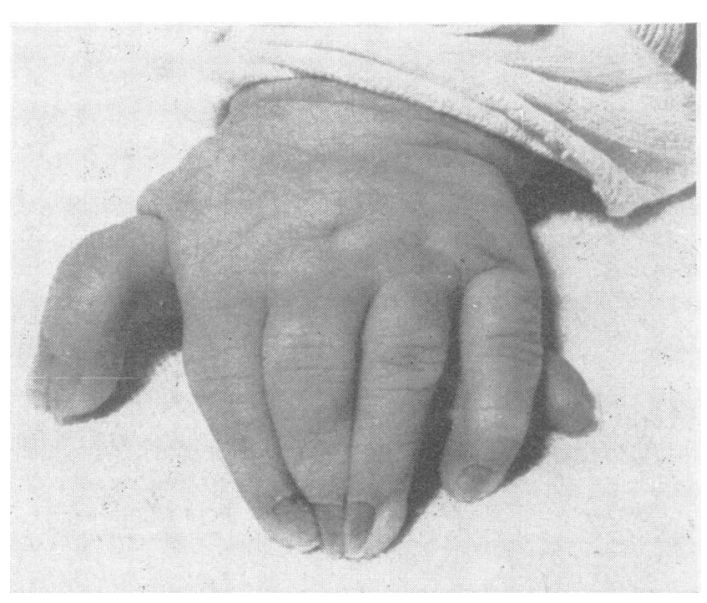

FIG. 4. Left hand of the propositus. 


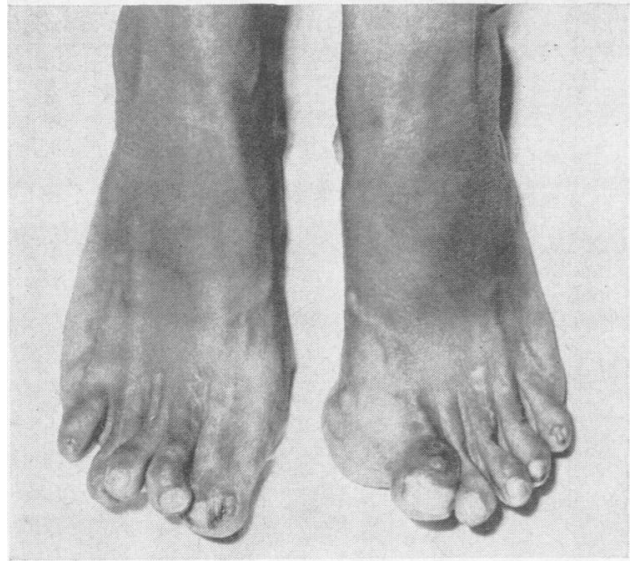

FIG. 5. Feet of the mother (III.4) of the propositus.

was healthy except for late onset diabetes at the age of 57 and was of low stature. She was 30 years old at the birth of III.4.

The only other member of the family who had Marfan's syndrome was IV.15 a 5-year-old girl who was $118.5 \mathrm{~cm}$ high (50th centile for age $6 \frac{1}{2}$ ); she was taller than her normal 7-year-old sister (IV.14) who was only $114.5 \mathrm{~cm}$ tall in keeping with the short stature of the family. IV.15 has shown the classical picture of Marfan's syndrome. She had subluxation of the lenses, bluish sclerae and narrow palate. Her span, $120 \mathrm{~cm}$, was larger than her height and she had a pigeon breast. Her fingers and toes were very long in sharp contrast to her normal sister. She had hyperextansibility of the joints.

In addition to the propositus, his mother, and grandfather there were 14 other members of the family affected with polysyndactyly. Altogether there were seven males and 10 females affected. The gene was fully penetrant with variable expressivity.

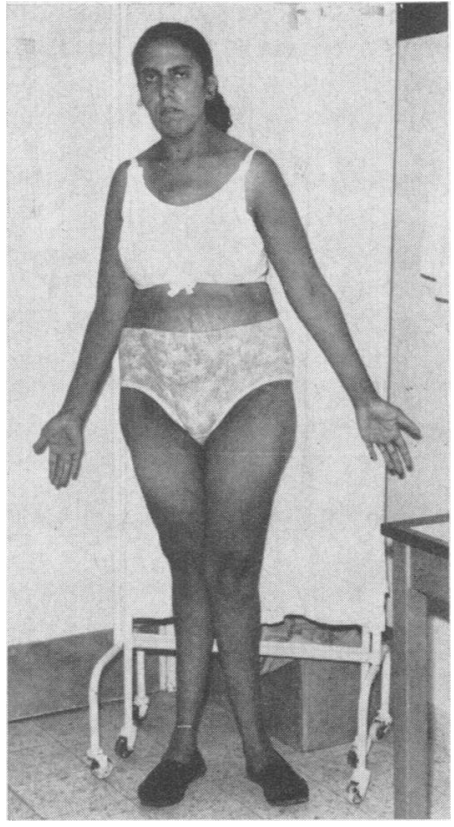

FIG. 7. Mother (age 27) of the propositus.

Discussion

The effects of parental age on the occurrence of a new mutation for Marfan's syndrome were demonstrated by Murdoch, Walker, and McKusick (1972). The mother (III.4) of the present propositus was a sporadic case of Marfan's syndrome who inherited the gene for polysyndactyly from her father. Her parents were somewhat above average age at her birth. The association of Marfan's syndrome and polysyndactyly in the same person has

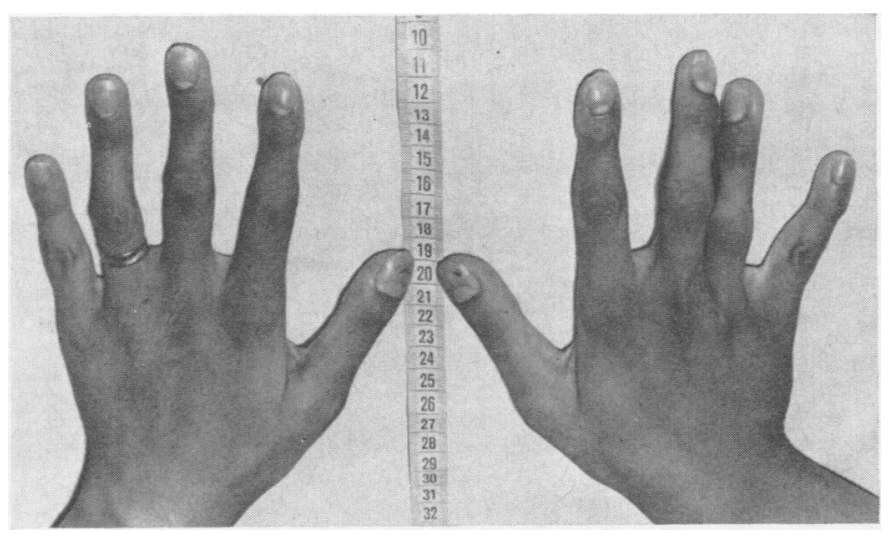

FIG. 6. Hands of the mother of the propositus. 
apparently not been previously described. This association is most probably fortuitous as III.4 is the only one in this family to show both conditions and the two genes seem to segregate independently in her offspring: IV.14 is normal, IV.15 has only Marfan's syndrome, IV.16 (the propositus) has only polysyndactyly. Theoretically the two genes could interact if they are present in the same individual but we have no evidence for such interaction. Assuming that the two genes are not linked, the mother (III.4) of the propositus has only a $25 \%$ chance of having a normal child if she becomes pregnant again while she has $25 \%$ risk of having a child affected with both polysyndactyly and Marfan's syndrome. She also has risk of $25 \%$ each, for her child to be affected either by polysyndactyly alone or by Marfan's syndrome alone. This situation was fully explained to the mother who felt that in view of this risk her family was completed and she elected to be sterilized.

\section{REFERENCES}

Goodman, R. M. (1965). A family with polysyndactyly and other anomalies. Fournal of Heredity, 56, 37-38.

McClintic, B. S. (1935). Five generations of polydactylism. Fournal of Heredity, 26, 141-144.

Murdoch, J. L., Walker, B. A., and McKusick, V. A. (1972). Parental age effects on the occurrence of new mutations for the Marfan syndrome. Annals of Human Genetics, 35, 331-336.

Temtamy, S. and McKusick, V. A. (1969). Synopsis of hand malformations with particular emphasis on genetic factors. Birth Defects: Original Article Series, 5, No. 3, pp. 125-184. The National Foundation-March of Dimes, New York.

Thomsen, O. (1927). Einige Eigentümlichkeiten der Erblichen Poly-und Syndaktylie bei Menschen. Acta Medica Scandinavica, 65, 609-644. 